\title{
COMMUNITY PHARMACY ROLE IN UNIVERSAL HEALTH COVERAGE IN MOMBASA COUNTY
}

\author{
Kailong J. M. ${ }^{1}$ \\ ${ }^{1}$ Assistant lecturer, \\ Department of Medical Sciences, \\ School of pure and Health Sciences, \\ Technical University of Mombasa, \\ Kenya
}

\author{
Aggrey A. ${ }^{2}$ \\ ${ }^{2}$ Lecturer, \\ Department of Mathematics and Physics, \\ School of Pure and Health Sciences, \\ Technical University of Mombasa, \\ Kenya
}

\author{
Mulinya S. ${ }^{3}$ \\ ${ }^{3}$ Pharmaceutical Technologist, \\ Department of Medical Sciences, \\ School of Pure and Applied Sciences, \\ Technical University of Mombasa, \\ Kenya
}

Article DOI: $\underline{\text { https://doi.org/10.36713/epra5722 }}$

\begin{abstract}
Community pharmacy role in universal health coverage was a qualitative study that entailed close contact to the role played by community pharmacies in healthcare provision. As a "small healthcare" in provision of pharmaceutical services, community pharmacies are required to be included in realization of Universal Health Coverage in Mombasa since it is among the Big 4 Agenda of the national government $(\mathrm{MOH}, 2013)$. The objective of the study was to determine community pharmacy role in universal health coverage. A descriptive cross sectional study design was used to collect both qualitative and quantitative data and the design estimate the prevalence of the outcome of interest commonly for the purpose of public health planning. A sample size of 196 was calculated using fishers formula. Data was collected using in-depth interviews and structured questionnaire were administered on a target population of community pharmacies health providers and clients seeking services respectively. The collected data was analysed using SPSS version 20 and interpreted using tables and pie charts. On community pharmacy practitioners respondents; $58 \%$ were male, $90.3 \%$ diploma holders in pharmacy, $39.8 \%$ registered with $P P B$ and $65 \%$ had practised for less than two years. $78 \%$ of the respondents agree that community pharmacy has a role in UHC and there was $74 \%$ affordability of community pharmacy medicines. Bivariate analysis findings show that training and inspection on UHC $(P=0.003)$ Covid $19(p=0.000)$ and inspection fee $(p=0.000)$. Accessibility; location of community pharmacies $(p=0.000)$ and doctors attitudes $(p=0.000)$. Essential medicines; acyclovir 200mg tablets $(p=0.000)$, chlorpromazine $100 \mathrm{mg}$ tablets $(p=0.000)$ and tetanus toxoid vaccine $(p=0.000)$. Key determinants of community pharmacy role in UHC were diploma (AOR 666.7; CI 129.6-3429.5), Erythromycin 125mg suspension (AOR 120.3; CI 15.4-940.8), Acyclovir 200mg tablets (AOR 46.823; CI 17.7-124.1) and Occupation (AOR 45.271; CI 15.363-133.404. The study recommends reduction of tax on essential medicines, $\mathrm{MOH}$ revise the $U H C$ policy to incorporate community pharmacies and empowerment on management of controlled drugs and vaccines in order to realize effective and efficient UHC in Kenya
\end{abstract}




\section{INTRODUCTION}

Universal Health Coverage may be defined as ensuring all people use the promotive, curative, rehabilitative and palliative health services they need of sufficient quality and effective, while ensuring the use of such services does not expose the user to any financial hardship which has continued to dominate healthcare (Robertson et al; 2015). The goal of UHC is to ensure that all people obtain the health services they need without suffering financial destitution when paying for them.

WHO identifies FOUR elements which are necessary towards the realization of universal health coverage. The elements are; strong, efficient, well-run health system, system of financing health services, access to essential medicines and technologies and sufficient capacity of well-trained motivated health workers (WHO, 2010).

Roles of a community pharmacy include provision of over the counter and prescriptions medicines, give pharmaceutical information, compounding which is small scale manufacture of drugs to meet the patients demand, checking and dispensing of prescription drugs with care, accuracy and legality, procurement that is, purchasing of medicines, storage, documentation of prescriptions and medicines, guiding and counseling patients on drug adherence and compliance and engaging in health promoting programs such as vaccination, identification of number of births and deaths. Through all this a community pharmacy becomes so essential in provision of health services nationwide (Lore, 2008).

The vision of health services in Kenya is to provide equitable and affordable service to all Kenyans via both preventive and curative care $(\mathrm{MOH}, 2013)$. A community pharmacy is a retail shop which provides prescription drugs, over the counter drugs, among other products but basically pharmaceutical related services (Bhise \& Yadav, 2006). Services are provided by trained professional who have gone through a full training and approved by the Pharmacy and Poison Board (PPB). The PPB is the Drug regulatory authority established under the Pharmacy and Poison Act, Chapter 244 of the laws of Kenya (PPB, 2012). The Board regulates the practice of pharmacy, the manufacture and the trade in drugs and poisons (Lore, 2008)

Pharmacists and Pharmaceutical technologists are expert in pharmaceutical care, pharmacotherapy and health promotion. Therefore, Community Pharmacy play a great role in health of individuals hence making it a means to Universal Health Coverage. UHC is a health care system in which all residents of a particular country or region are assured access to health care. It is generally organized around providing either all residents or only those who cannot afford on their own with either health services or the means to acquire them, with the end goal of improving health outcomes (WHO, 2010).

The purpose of this study was to determine the role of the community pharmacy in UHC being one of the BIG 4 agenda of the National Government through the Ministry of Health (GOK, 2018).

\section{OBJECTIVES}

\section{General Objective}

To determine Community Pharmacy role in Universal Health Coverage in Kenya

\section{Specific Objectives}

a) To determine factors to be considered by the government in promoting universal health coverage and health equity.

b) To establish the affordability of health services in community pharmacies.

c) To determine the accessibility of health care services in community pharmacy.

d) To evaluate the available essential medicines in community pharmacy.

\section{METHODOLOGY}

A descriptive Cross sectional study design was used in the study. The design is able to estimate the prevalence of the outcome of interest for a given population, commonly for the purpose of public health planning (Levin, 2006). Both qualitative and quantitative data was collected from clients seeking health services at the community pharmacy as well as pharmacy practitioners working at the community pharmacy. All respondents above 18 years of age and were willing to participate via consenting were recruited

\section{Study Site}

The study was carried out in Mombasa town in Mombasa County 001 located at the coastal region of Kenya. It has an approximate of 1000 community pharmacies which provide the community with pharmaceutical services (PPB, 2019).

\section{Sample Size Determination}

The sample size was calculated using Fisher's formula (Mugenda, 2006)

$$
\begin{aligned}
& \text { Where; } \quad \mathrm{n}=\frac{\mathrm{z}^{2} \mathrm{qp}}{\mathrm{d}^{2}} \\
& \mathrm{n}=\text { Desired sample size } \\
& \mathrm{Z}=\text { Standard normal deviation (1.96) } \\
& \mathrm{p}=\text { Anticipated population proportion }(15 \%) \\
& \mathrm{q}=(1-\mathrm{p}) \\
& d=\text { Allowable error }(5 \%)
\end{aligned}
$$




$$
\begin{gathered}
\mathrm{n}=\frac{(1.92)^{2}(0.15)(0.85)}{(0.05)^{2}} \\
=196
\end{gathered}
$$

\section{SAMPLING METHOD}

A snow ball random sampling was used to recruit subjects into the study among various community pharmacies in Mombasa County. Data collection process was done daily from Monday to Friday at $8 \mathrm{am}$ to $5 \mathrm{pm}$ until the desired sample size was obtained.

\section{DATA MANAGEMENT}

The collected data was edited, transcribed and coded before entry into the SPSS computer software for analysis. All filled questionnaires were kept safe in a lockable cupboard and keys kept by researcher only. The collected data was analyzed based on the study variables, then presented by the use of tables, bar graphs and pie charts

\section{RESULTS}

Figures

\section{COMMUNITY PHARMACY ROLE IN UHC}

$$
\square \text { YES } \square \text { NO }
$$

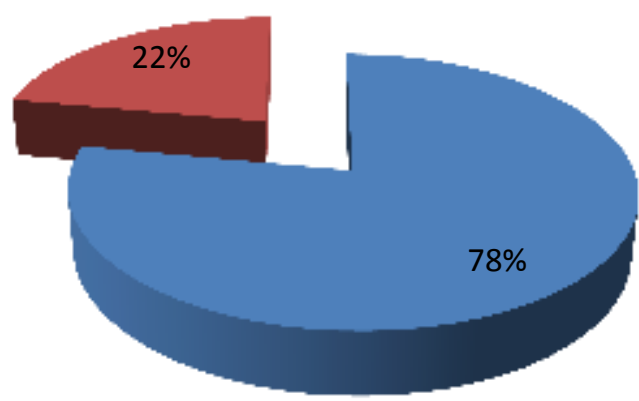

Figure 1: Community pharmacy role in UHC

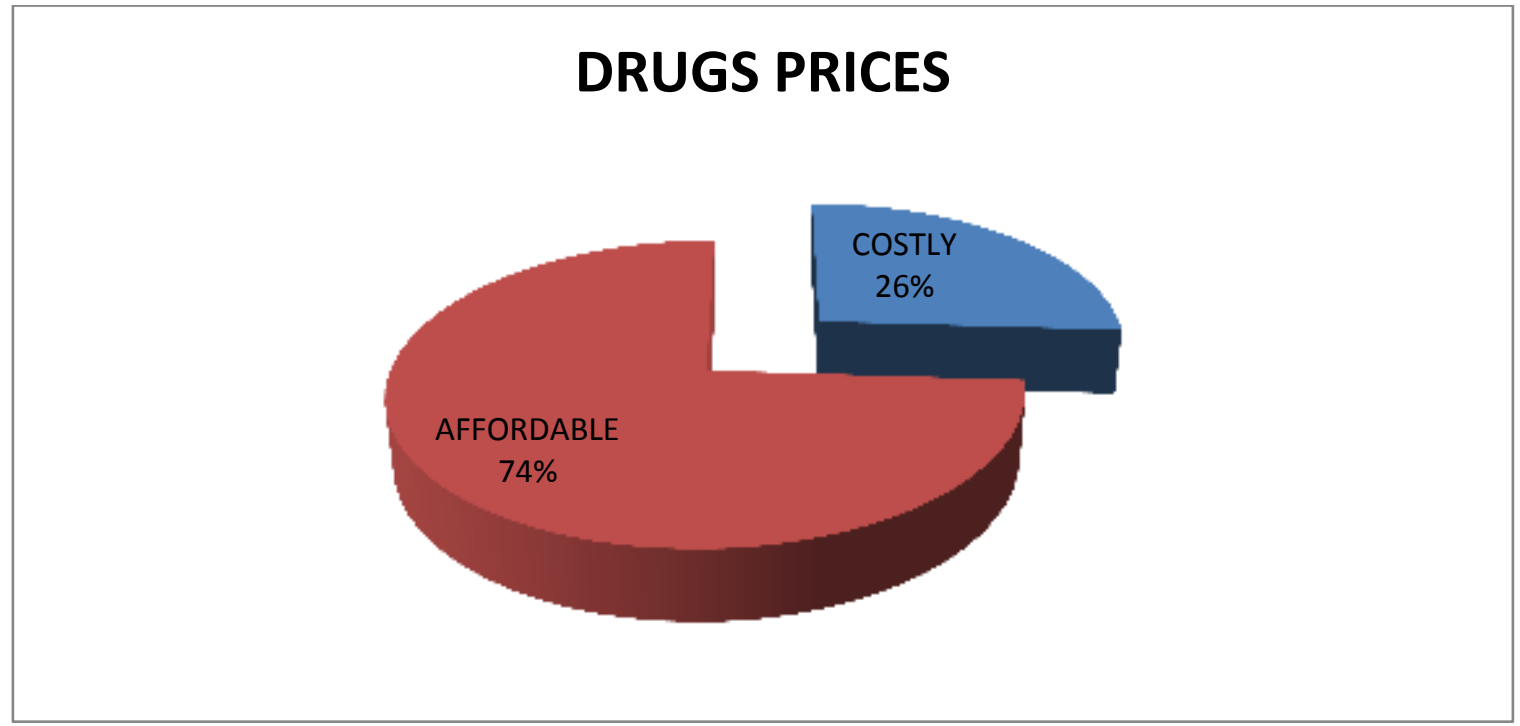

Figure 2: Drugs affordability

Tables 


\begin{tabular}{ccccc}
\multirow{2}{*}{ Variable } & $\begin{array}{c}\text { Table 1: Socio-demographic factors of the respondents } \\
\text { Category }\end{array}$ & $\begin{array}{c}\text { Frequency } \\
\text { (N=196) }\end{array}$ & \multicolumn{2}{c}{$\begin{array}{c}\text { Community pharmacy role in } \\
\text { UHC }\end{array}$} \\
& & & Yes $(\mathrm{n}=153)$ & No $(\mathrm{n}=43)$ \\
Gender & Male & $114(58 \%)$ & $78(51 \%)$ & $36(83.7 \%)$ \\
& Female & $82(42 \%)$ & $75(49 \%)$ & $7(16.3 \%)$ \\
Education & Diploma & $177(90.3 \%)$ & $150(93 \%)$ & $3(7 \%)$ \\
& Degree & $19(9.7 \%)$ & $3(7 \%)$ & $40(93 \%)$ \\
Registration with PPB & Yes & $78(39.8 \%)$ & $76(49.7 \%)$ & $2(4.7 \%)$ \\
& No & $118(60.2 \%)$ & $77(50.3 \%)$ & $41(95.3 \%)$ \\
Practicing duration & $<2$ years & $128(65.3 \%)$ & $86(56.2 \%)$ & $42(97.7 \%)$ \\
Occupation & $>2$ years & $68(34.7 \%)$ & $67(43.8 \%)$ & $1(2.3 \%)$ \\
& Employed & $165(85.1 \%)$ & $148(96.7 \%)$ & $17(39.5 \%)$ \\
& Student /intern & $31(14.9 \%)$ & $5(3.3 \%)$ & $26(60.5 \%)$
\end{tabular}

\begin{tabular}{|c|c|c|}
\hline & & \\
\hline Variable & Category & Frequency \\
\hline Training & & \\
\hline UHC & Yes & $79(40.3 \%)$ \\
\hline & No & $117(59.7 \%)$ \\
\hline ADR & Yes & $78(39.8 \%)$ \\
\hline & No & $118(60.2 \%)$ \\
\hline Malaria management & Yes & $137(69.9 \%)$ \\
\hline & No & $59(30.1 \%)$ \\
\hline Covid 19 & Yes & $98(50 \%)$ \\
\hline & No & $98(50 \%)$ \\
\hline TB/HIV & Yes & $138(70.4 \%)$ \\
\hline & No & $58(29.6 \%)$ \\
\hline Inspection (PPB) & & \\
\hline Premise & Yes & $196(100 \%)$ \\
\hline & No & $0(0 \%)$ \\
\hline Inspection fee & Charged & $39(19.9 \%)$ \\
\hline & Not charged & $157(80.1 \%)$ \\
\hline Frequency & Often & $117(59.7 \%)$ \\
\hline & Rarely & $79(40.3 \%)$ \\
\hline Inspectors attitude & Very good & $20(10.2 \%)$ \\
\hline & Good & $98(50 \%)$ \\
\hline & Bad & 78(39.8) \\
\hline Guidelines provision & Yes & $158(80.6 \%)$ \\
\hline & No & 38(19.4\%) \\
\hline $\begin{array}{l}\text { GOK commodities } \\
\text { (free) }\end{array}$ & & \\
\hline Condoms & Yes & $0(0 \%)$ \\
\hline & No & $196(100 \%)$ \\
\hline HIV test kits & Yes & $20(10.2 \%)$ \\
\hline & No & $176(89.8 \%)$ \\
\hline Family planning & Yes & $0(0 \%)$ \\
\hline & No & $196(100 \%)$ \\
\hline PEP & Yes & $0(0 \%)$ \\
\hline & No & $196(100 \%)$ \\
\hline
\end{tabular}

Community pharmacy role in UHC Yes $(n=153) \quad$ No $(n=43)$

$70(45.8 \%) \quad 9(20.9 \%)$

$83(54.2 \%) \quad 34(79.1 \%)$

$72(47.1 \%) \quad 6(14 \%)$

$81(52.9 \%) \quad 37(86 \%)$

$108(70.6 \%) \quad 29(67.4 \%)$

$45(29.4 \%) \quad 14(32.6 \%)$

$98(64.1 \%) \quad 0(0 \%)$

$55(35.9 \%) \quad 43(100 \%)$

$121(79.1 \%) \quad 17(39.5 \%)$

$32(20.9 \%) \quad 26(60.5 \%)$

$153(100 \%) \quad 43(100 \%)$

$0(0 \%) \quad 0(0 \%)$

$39(25.5 \%) \quad 0(0 \%)$

$114(74.5 \%) \quad 43(100 \%)$

$100(65.4 \%) \quad 17(39.5 \%)$

$53(34.6 \%) \quad 26(60.5 \%)$

$20(13.1 \%) \quad 0(0 \%)$

65(42.5\%) 33(76.7\%)

$68(44.4 \%) \quad 10(23.3 \%)$

$153(100 \%) \quad 5(11.6 \%)$

$0(0 \%) \quad 38(88.4 \%)$

$\begin{array}{ll}0(0 \%) & 0(0 \%) \\ 153(100 \%) & 43(100 \%) \\ 20(13.1 \%) & 0(0 \%) \\ 133(86.9 \%) & 43(100 \%) \\ 0(0 \%) & 0(0 \%) \\ 153(100 \%) & 43(100 \%) \\ 0(0 \%) & 0(0 \%) \\ 153(100 \%) & 43(100 \%)\end{array}$




$\begin{array}{cllll}\text { Pre - EP } & \text { Yes } & 0(0 \%) & 0(0 \%) & 0(0 \%) \\ & \text { No } & 196(100 \%) & 153(100 \%) & 43(100 \%)\end{array}$

Table 3: Accessibility to community pharmacy and Affordability of drugs

Variable

$\begin{array}{lll}\text { Distance } & & \\ & <1 \mathrm{~km} & 160(81.6 \%) \\ \text { Operation time } & >1 \mathrm{~km} & 36(18.4 \%) \\ & \text { Reliable } & 136(69.4 \%) \\ \text { Client health needs } & \text { Unreliable } & 60(30.4 \%) \\ & \text { Met } & 158(80.6 \%) \\ \text { Quality of services } & \text { Unmet } & 38(19.4 \%) \\ & \text { Very good } & 135(68.9 \%) \\ \text { Doctors attitudes } & \text { Good } & 61(31.1 \%) \\ & \text { Satisfactory } & 158(80.6 \%) \\ & \text { Unsatisfactory } & 38(19.4 \%)\end{array}$

Affordability of drugs

$\begin{array}{ll}\text { Affordable }(\mathrm{n}=145) & \text { Costly }(\mathrm{n}=51) \\ 140(96.6 \%) & 20(39.2 \%) \\ 5(3.4 \%) & 31(60.8 \%) \\ 136(93.8 \%) & 0(0 \%) \\ 9(6.2 \%) & 51(100 \%) \\ 145(100 \%) & 13(25.5 \%) \\ 0(0 \%) & 38(74.5 \%) \\ 60(41.8 \%) & 1(2 \%) \\ 85(58.2 \%) & 50(98 \%) \\ 143(98.6 \%) & 15(29.4 \%) \\ 2(1.4 \%) & 36(70.6 \%)\end{array}$

\section{Variable}

Gender

Education

Registration with

PPB

Practicing

duration

Occupation

Variable

Training

UHC Yes

No

ADR Yes

Malaria management Yes

Covid 19

TB/HIV

Inspection (PPB)

Yes

No

Yes

No

Table 4: Bivariate analysis on socio demographic factors of the respondents

\section{Category}

Male

Female

Diploma

Degree

No

$<2$ years

$>2$ years

Employed

Student / intern

\section{Community pharmacy role in}

UHC

Yes $(\mathrm{n}=153)$

$78(51 \%)$

$75(49 \%)$

$150(93 \%)$

$3(7 \%)$

76(49.7\%)

77(50.3\%)

$86(56.2 \%)$

67(43.8\%)

148(96.7\%)

$5(3.3 \%)$

$1(2.3 \%)$
Df

No $(\mathrm{n}=43)$

$36(83.7 \%)$

$7(16.3 \%)$

$3(7 \%)$

$40(93 \%)$

2(4.7\%)

$41(95.3 \%)$

42(97.7\%)

$17(39.5 \%)$

26(60.5\%)
Chi square

$1 \quad 14.787$

$1 \quad 162.531$

28.398

25.472

82.474
$P$ - value

0.000

0.000

0.000

0.000

0.000

Table 5: Bivariate analysis health promotion in equity

\section{Category}

Community pharmacy has a role

$$
\text { in UHC }
$$

$$
\text { Yes }(n=153) \quad \text { No }(n=43)
$$

$\begin{array}{ll}70(45.8 \%) & 9(20.9 \%) \\ 83(54.2 \%) & 34(79.1 \%) \\ 72(47.1 \%) & 6(14 \%) \\ 81(52.9 \%) & 37(86 \%) \\ 108(70.6 \%) & 29(67.4 \%) \\ 45(29.4 \%) & 14(32.6 \%) \\ 98(64.1 \%) & 0(0 \%) \\ 55(35.9 \%) & 43(100 \%) \\ 121(79.1 \%) & 17(39.5 \%) \\ 32(20.9 \%) & 26(60.5 \%)\end{array}$

Chi square

\begin{tabular}{ccc}
\multicolumn{3}{c}{ square } \\
1 & 8.595 & 0.003 \\
1 & 15.354 & 0.000 \\
1 & 0.158 & 0.691 \\
1 & 55.085 & 0.000 \\
1 & 25.2 & 0.000
\end{tabular}

$P$ - value
Df 


\begin{tabular}{|c|c|c|c|c|c|c|}
\hline \multirow[t]{2}{*}{ Premise } & Yes & $153(100 \%)$ & $43(100 \%)$ & 1 & - & - \\
\hline & No & $0(0 \%)$ & $0(0 \%)$ & & & \\
\hline \multirow[t]{2}{*}{ Inspection fee } & Charged & $39(25.5 \%)$ & $0(0 \%)$ & 1 & 13.684 & 0.000 \\
\hline & Not charged & $114(74.5 \%)$ & $43(100 \%)$ & & & \\
\hline \multirow[t]{2}{*}{ Frequency } & Often & $100(65.4 \%)$ & $17(39.5 \%)$ & 1 & 9.304 & 0.002 \\
\hline & Rarely & $53(34.6 \%)$ & $26(60.5 \%)$ & & & \\
\hline \multirow[t]{3}{*}{ Inspectors attitude } & Very good & $20(13.1 \%)$ & $0(0 \%)$ & 2 & 17.288 & 0.000 \\
\hline & Good & $65(42.5 \%)$ & $33(76.7 \%)$ & & & \\
\hline & Bad & $68(44.4 \%)$ & $10(23.3 \%)$ & & & \\
\hline \multirow[t]{2}{*}{ Guidelines provision } & Yes & 153(100\%) & $5(11.6 \%)$ & 1 & 167.728 & 0.000 \\
\hline & No & $0(0 \%)$ & $38(88.4 \%)$ & & & \\
\hline \multicolumn{7}{|l|}{$\begin{array}{l}\text { GOK } \\
\text { (free) }\end{array}$} \\
\hline \multirow[t]{2}{*}{ Condoms } & Yes & $0(0 \%)$ & $0(0 \%)$ & 1 & - & - \\
\hline & No & $153(100 \%)$ & $43(100 \%)$ & & & \\
\hline \multirow[t]{2}{*}{ HIV test kits } & Yes & $20(13.1 \%)$ & $0(0 \%)$ & 1 & 6.26 & 0.012 \\
\hline & No & 133(86.9\%) & $43(100 \%)$ & & & \\
\hline \multirow[t]{2}{*}{ Family planning } & Yes & $0(0 \%)$ & $0(0 \%)$ & - & - & - \\
\hline & No & $153(100 \%)$ & $43(100 \%)$ & & & \\
\hline \multirow[t]{2}{*}{ PEP } & Yes & $0(0 \%)$ & $0(0 \%)$ & - & - & - \\
\hline & No & $153(100 \%)$ & $43(100 \%)$ & & & \\
\hline \multirow[t]{2}{*}{ Pre - EP } & Yes & $0(0 \%)$ & $0(0 \%)$ & - & - & - \\
\hline & No & $153(100 \%)$ & $43(100 \%)$ & & & \\
\hline \multicolumn{7}{|c|}{ Table 6: Bivariate analysis on community pharmacy and Affordability of drugs } \\
\hline \multirow[t]{2}{*}{ Variable } & Category & Affordal & bility of drugs & Df & $\underset{\text { souare }}{\text { Chi }}$ & $P$ - value \\
\hline & & $\begin{array}{c}\text { Affordable } \\
(\mathrm{n}=145)\end{array}$ & Costly (n=51) & & & \\
\hline \multirow[t]{2}{*}{ Distance } & $<1 \mathrm{~km}$ & $140(96.6 \%)$ & $20(39.2 \%)$ & 1 & 82.723 & 0.000 \\
\hline & $>1 \mathrm{~km}$ & $5(3.4 \%)$ & $31(60.8 \%)$ & & & \\
\hline \multirow[t]{2}{*}{ Operation time } & Reliable & $136(93.8 \%)$ & $0(0 \%)$ & 1 & 156.259 & 0.000 \\
\hline & Unreliable & $9(6.2 \%)$ & $51(100 \%)$ & & & \\
\hline \multirow[t]{2}{*}{ Client health needs } & Met & $145(100 \%)$ & $13(25.5 \%)$ & 1 & 134.023 & 0.000 \\
\hline & Unmet & $0(0 \%)$ & $38(74.5 \%)$ & & & \\
\hline \multirow[t]{2}{*}{ Quality of services } & Very good & $60(41.8 \%)$ & $1(2 \%)$ & 2 & 27.348 & 0.000 \\
\hline & Good & $85(58.2 \%)$ & $50(98 \%)$ & & & \\
\hline \multirow[t]{2}{*}{ Doctors attitudes } & Satisfactory & 143(98.6\%) & $15(29.4 \%)$ & 1 & 115.632 & 0.000 \\
\hline & Unsatisfactory & $2(1.4 \%)$ & $36(70.6 \%)$ & & & \\
\hline
\end{tabular}




\section{Variable}

Paracetamol 500mg tablets

Chlorpheniramine $2 \mathrm{mg}$ suspension

Multivitamin tablets

Metoclopramide $10 \mathrm{mg}$ tablets

Activated charcoal tablets

Albendazole 200mg suspension

Metronidazole 400mg tablets

Erythromycin $125 \mathrm{mg}$ suspension

Fluconazole $200 \mathrm{mg}$ tablets

Acyclovir 200mg tablets

Doxycycline 100mg capsules

Nifedipine $20 \mathrm{mg}$ tablets

Metforming 500mg tablets

Chlorpromazine $100 \mathrm{mg}$ tablets

Phenobarbitone 30mg tablets

Antirabies vaccine

Oral typhoid vaccine

Hepatitis B vaccine

Pentavalent vaccine

Tetanus toxoid (T.T) vaccine
Table 7: Bivariate analysis on essential drugs Category Affordability of drugs

Affordable $(n=145)$

Yes

No

Yes

No

Yes

No

Yes

No

Yes

No

Yes

No

Yes

No

Yes

No

Yes

No

Yes

No

Yes

No

Yes

No

Yes

No

Yes

No

Yes

No

Yes

No

Yes

No

Yes

No

Yes

No

Yes

No

$58(39.9 \%)$

95(60.1\%)
Costly $(n=51)$

153(100\%)

$0(0 \%)$

$153(100 \%)$

$0(0 \%)$

$153(100 \%)$

$0(0 \%)$

$153(100 \%)$

$0(0 \%)$

$153(100 \%)$

$0(0 \%)$

$153(100 \%)$

$0(0 \%)$

43(100\%)

$0(0 \%)$

24(55.8\%)

$19(44.2 \%)$

$43(100 \%)$

$0(0 \%)$

$12(27.9 \%)$

$31(72.1 \%)$

43(100\%)

$0(0 \%)$

43(100\%)

$0(0 \%)$

$43(100 \%)$

$0(0 \%)$

$6(14 \%)$

$37(86 \%)$

$10(23.4 \%)$

$33(76.7 \%)$

$0(0 \%)$

43(100\%)

$0(0 \%)$

$43(100 \%)$

$0(0 \%)$

$43(100 \%)$

$0(0 \%)$

$43(100 \%)$

$0(0 \%)$

$43(100 \%)$
Df

Chi square $\quad P$ - value

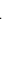

69.422

0.000

1

94.154

0.000

28.630

0.000

1

15.760

0.000
1

23.152
0.000 


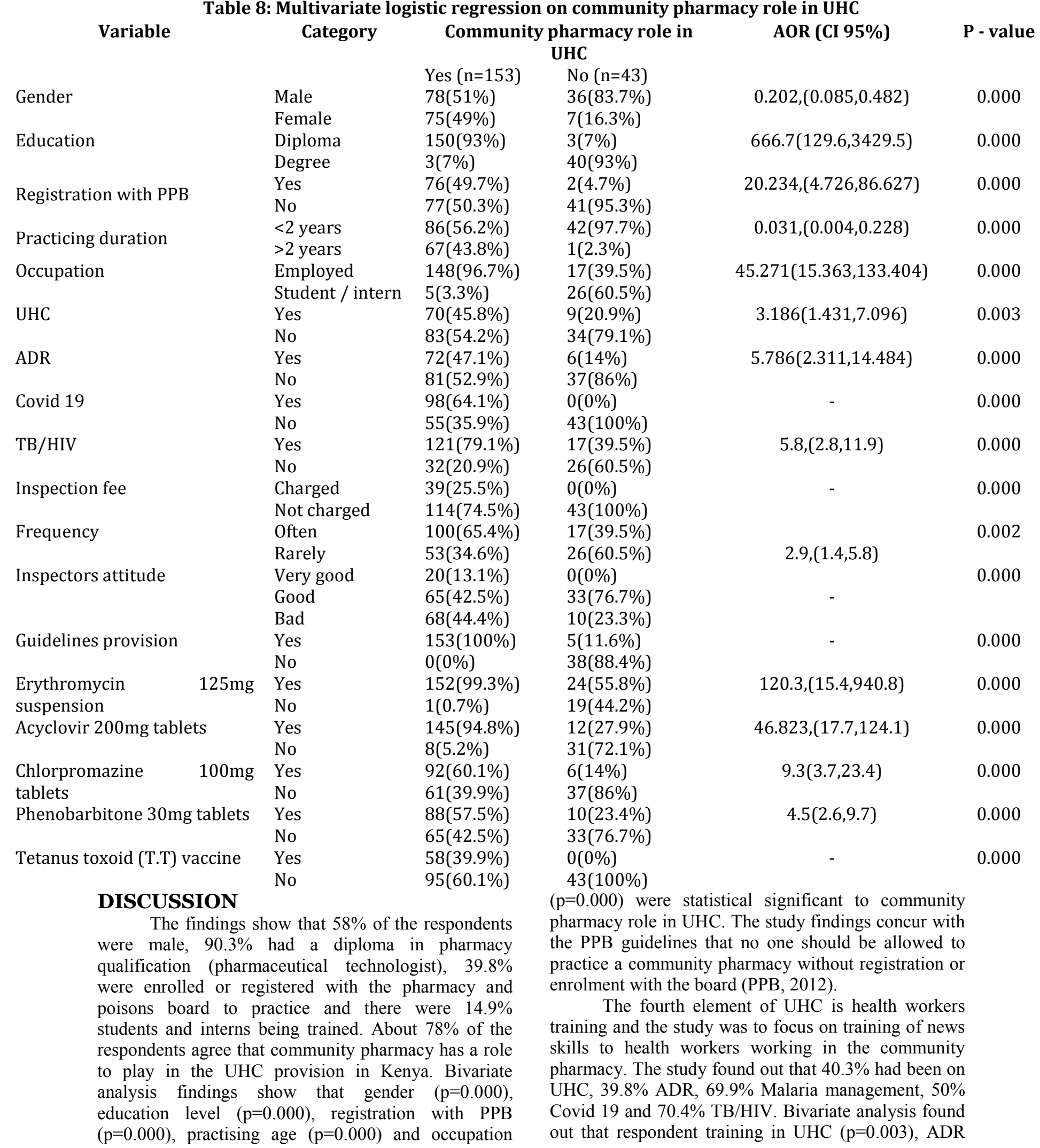


(0.000), Covid $19(\mathrm{p}=0.000)$ and TB/HIV $(\mathrm{p}=0.000)$ were statistically significant to community pharmacy role in UHC. Therefore, based on the study findings all community pharmacies practitioners should benefit from the MOH skill training to be able to render better health outcomes to Kenyans. Other studies by (Mwangi et al; 2015 and Kibui et al; 2015) demonstrates how health workers in private practice must receive training offered by the $\mathrm{MOH}$ in order to empower their service delivery to Kenyans.

On the part of government (PPB) role, the study found out that $100 \%$ of the community pharmacies had undergone inspection process, $19.9 \%$ claim they were charged premise inspection fee yet the process should be free of charge (PPB, 2012), 59.7\% agree that inspection process has been done on regular basis, $60.2 \%$ agree the inspectors do their work with good attitude and $80.6 \%$ of the respondents were provided with inspection guidelines by the PPB inspectors. Bivariate analysis finding show that inspection fee $(p=0.000)$, frequency of the inspection exercise $(\mathrm{p}=0.002)$, attitudes of inspectors $(\mathrm{p}=0.000)$ and provision of inspection guidelines $(\mathrm{p}=0.000)$ to be statistical significant to community pharmacy role in UHC

Study was also interested to identify the government role in partnering with the community pharmacies to enhance healthcare reach to the community with certain commodities offered for free to the public by the public hospitals. The study found out that the supply of condoms $(0 \%)$, family planning commodities $(0 \%)$, HIV test kits $(10.2 \%)$, post exposure prophylaxis to HIV ( $0 \%)$, and Pre exposure prophylaxis to HIV $(0 \%)$. The bivariate analysis found out that HIV test commodities $(\mathrm{p}=0.012)$ to be statistically significant to community pharmacy role in UHC

The other element of UHC is access to essential medicines and the study was interested to identify availability of essential medicines at the community pharmacy. The study found out that for general drugs; paracetamol 500mg tablets $(100 \%)$, Chlorpheniramine $2 \mathrm{mg}$ suspension $(100 \%)$, multivitamin tablets $(100 \%)$, Metoclopramide $10 \mathrm{mg}$ tablets $(100 \%)$, activated charcoal tablets $(100 \%)$ and Albendazole $200 \mathrm{mg}$ suspension $(100 \%)$. Antimicrobial drugs; metronidazole $400 \mathrm{mg}$ tablets $(100 \%)$, erythromycin $125 \mathrm{mg}$ suspension $(99.3 \%$ ), fluconazole $200 \mathrm{mg}$ tablets $(100 \%)$, acyclovir $200 \mathrm{mg}$ tablets $(94.8 \%)$ and doxycycline $100 \mathrm{mg}$ capsules $(100 \%)$. Special drugs; nifedipine $20 \mathrm{mg}$ tablets $(100 \%)$, metformin $500 \mathrm{mg}$ tablets $(100 \%)$, chlorpromazine $100 \mathrm{mg}$ tablets $(60.1 \%)$ and phenobarbitone $30 \mathrm{mg}$ tablets $(57.5 \%)$. Vaccines; oral typhoid vaccine $(0 \%)$, hepatitis $\mathrm{B}$ vaccine $(0 \%)$, pentavalent vaccine $(0 \%)$ and tetanus toxoid vaccine $(39.9 \%)$. Based on bivariate analysis, erythromycin $125 \mathrm{mg}$ suspension $(\mathrm{p}=0.000)$, Acyclovir $200 \mathrm{mg}$ tablets $(\mathrm{p}=0.000)$, chlorpromazine $100 \mathrm{mg}$ tablets $(\mathrm{p}=0.000)$ and Phenobarbitone $30 \mathrm{mg}$ tablets $(\mathrm{p}=0.000)$. The UHC is very clear on accessibility of essential medicines and technologies (WHO, 2012). The Kenyan constitution 2010, state that it is the right of every Kenyan to access quality health care (Constitution of Kenya, 2010). Key determinants of community pharmacy role in UHC were diploma (AOR 666.7; CI 129.6-3429.5), Erythromycin 125mg suspension (AOR 120.3; CI 15.4940.8), Acyclovir 200mg tablets (AOR 46.823; CI 17.7-124.1) and Occupation (AOR 45.271; CI 15.363133.404 .

The study also found out that $74 \%$ of the essential medicines were affordable. About $96.6 \%$ of the respondents access community pharmacies in a short distance of less than one kilometre from their residence, the community pharmacy meets their healthy needs $(100 \%), 41.8 \%$ of the respondents find community pharmacies to offer good and quality health services and $98.6 \%$ agree that doctors at the community pharmacy have satisfactory attitudes on patient care. The bivariate findings show that distance $(\mathrm{p}=0.000)$, operation time $(\mathrm{p}=0.000)$, client needs $(\mathrm{p}=0.000)$, quality of service $(\mathrm{p}=0.000)$ and doctors attitude $(\mathrm{p}=0.000)$ to statistically significant to community pharmacy role in UHC. The findings agree with the study by Beringer \& Remington (2006) whose findings show how community pharmacies are crucial in society needs with drugs and pharmaceutical services.

In Kenya, the government chose National Hospital Insurance Fund (NHIF) as an official vehicle for successful implementation of universal health coverage for the country and it covers treatment of the insurance beneficiaries at both public and private hospitals (Munge et al; 2015). This means NHIF beneficiaries are not covered when the take their medications at the community pharmacies.

In Australia, Medicare is a universal health insurance scheme that covers all Australian citizens and permanent residents, with other programs covering specific groups, such as veterans or Indigenous Australians, and various compulsory insurance schemes cover personal injury resulting from workplace or vehicle incidents (Australian institute of health and welfare, 2018). Since 1990, the remuneration that pharmacists receive for dispensing Pharmaceutical Benefits Scheme (PBS) medicines and the regulations regarding the location of pharmacies have been governed by a series of agreements between the Australian Government and the Pharmacy Guild of Australia. The Sixth Community Pharmacy Agreement 
(6CPA) between the Australian Government and the Guild provides approximately $\$ 18.9$ billion to over 5000 community pharmacies for dispensing PBS medicines, providing pharmacy programs and services and for the Community Service Obligation arrangements with pharmaceutical wholesalers. This provides financial support to pharmaceutical wholesalers, supplying the full range of PBS medicines regardless of pharmacy location and the relative cost of supply. The CSO Funding Pool helps ensure that low volume PBS medicines are delivered to community pharmacies anywhere in Australia and that all PBS medicines are delivered to rural and remote community pharmacies (Vitry et al; 2015).

In England,NHS commits almost $£ 13$ billion to community pharmacy through its contractual framework, with a commitment to spend $£ 2.592$ billion over five years from 2019-2024. This significant investment recognises the contribution that community pharmacy has committed to making towards the delivery of the NHS Long Term Plan (Davies, 2013). Thus, learning from these two countries will enhance country health service delivery

\section{CONCLUSION}

UHC elements focus on strong, efficient and well runned health system, financing of health system, access to essential medicines and sufficient capacity of well trained motivated health workers. The community pharmacies have a role in UHC and this can be played through stocking essential pharmaceutical commodities that are effective and meets quality standards prescribed by the regulator (PPB). The community pharmacies require government support in order to get pharmaceutical products and establishment of their retail shop at affordable costs. It is always the government role to empower the all health workers with relevant training in order to ensure that they also render quality health care to the people

\section{RECOMMENDATIONS}

The study recommends the following based on it's study findings;

1. The community pharmacies should be empowered by the PPB to stock and manage controlled drugs and vaccines which are essential medicines in UHC

2. The government should consider either to reduce or withdraw tax on essential medicines and technologies as well give support young qualified persons put up a community pharmacy

3. The UHC policy in Kenya should be revised so that the community pharmacies becomes a stakeholder in provision affordable health services to the people given that they are accessible to many people

\section{REFERENCES}

1. Australian Institute of Health and Welfare (2018). Australia's Health 2018. Australia's Health. 16. AIHW

2. Ayugi, M. E. (2013). Uptake of community health strategy on service delivery and utilization in Kenya. European Scientific Journal, 9(23), 102111.

3. Babar, Z. (2015). Pharmacy practice research methods.

4. Beringer, P., \& Remington, J. P. (2006). Remington: The science and practice of pharmacy. Beyond UHC: monitoring health and social protection coverage in the context of tuberculosis care and prevention. PLoS medicine, 11(9), e100169

5. Bhise, S. B., \& Yadav, A. V. (2006). A text book of health education and community pharmacy. New Delhi, India: Nirali Prakashan

6. Boshoff, C. and Gray, B. (2004). The Relationship between service quality, customer satisfaction and buying intentions in the private hospital industry. South African Journal of Business Management, 35(4), 27-37.

7. Buong', J. A., Adhiambo, G. C., Kaseje, D. O. Mumbo, H. M., Odera O. and Carrin, G., James, C., Adelhardt, M., Doetinchem, O., Eriki, P., Hassan, M, \& Krech, $R . \quad$ (2007). Health financing reform in Kenya-assessing the social health insurance proposal. South African medical journal, 97(2), 130-135.

8. Davies, J. E. (2013). Community pharmacy businesses and community pharmacists (Doctoral dissertation, UCL (University College London)

9. De Leeuw, E. (2001). Global and local (glocal) health: the WHO healthy cities programme. Global Change and Human Health, 2(1), 34-45.

10. Feng Jing, F., Avery, G. C., \& Bergsteiner, $H$. (2011). Organizational climate and performance in retail pharmacies. Leadership \& Organization Development Journal, 32(3), 224-242.

11. Glickman, S. W., Baggett, K. A., Krubert, C. G., Peterson, E. D. and Schulman, K. A. (2007).

12. Promoting quality: The health care organization from a management perspective.International Journal of Quality Health Care, 19(6):341-348

13. GOK (2018). Big four agenda implementation status report

14. Houtkoop-Steenstra, H., \& Houtkoop-Steenstra, J. $P$. (2000). Interaction and the standardized survey interview: The living questionnaire. Cambridge University Press. Philadelphia: Lippincott Williams \& Wilkins.

15. KibuiA.W., Ruth K.M., Grace N., Ngesu N., Mwaniki I.N., Benard M. (2015). 'Health Policies in Kenyaand 
the New Constitution for Vision 2030', International Journal of Scientific Research and Innovative Technology 2(1):127.

16. Kelley, K., Clark, B., Brown, V., \& Sitzia, J. (2003). Good practice in the conduct and reporting of survey research. International Journal for Quality in health care, 15(3), 261-266.

17. Lambert, A. A., \& Lambert, A. A. (2014). Advanced pharmacy practice.

18. Leah Kimathi (2017). Challenges of the Devolved Health Sector in Kenya: Teething Problems or Systemic Contradictions? Africa Development, XLII, (1). 55-77

19. Levin, K. A. (2006). Study design III: Crosssectional studies. Evidence-based dentistry, 7(1), 24-25.

20. Lore, B. (2008). Optimising role of drugs in patient care. East African medical journal, 85(9), 417-418

21. Lönnroth, K., Glaziou, P., Weil, D., Floyd, K., Uplekar, M., \& Raviglione, M. (2014).

22. MOH.(2013b).Human Resources for Health and Health Infrastructure Norm and Standards. Nairobi, Kenya: $\mathrm{MOH}$.

23. MOH. (2013a). Kenya Service Availability and Readiness Assessment Mapping (SARAM) Report. Nairobi, Kenya: World HealthOrganization.

24. Mselle, L. T., Moland, K. M., Mvungi, A., Olsen, B. E., and Kohi, T. W. (2013). Why give birth in health facility? Users' and providers' accounts of poor quality of birth care in Kenya. BMC Health Services Research, 13, 174-184

25. Munge, K., Mulupi, S., \& Chuma, J. (2015). A critical analysis of the purchasing arrangements in Kenya: the case of the National Hospital Insurance Fund, Private and Community- based health insurance. London: RESYST.

26. Mwaniki, D.L. \& Dulo, C. (2008). "Migration of Health Workers in Kenya: The Impact on Health Service
Delivery." Regional Network for Equity in Health in East and SouthernAfrica.DiscussionPaperno.55,

27. Mwangi, C., 2013, 'Accessibility to the Kenyan Healthcare System: Barriers to Accessing Proper Healthcare', unpublished PhD thesis, Arcada University.

28. Noor, A. M., A. A. Amin, P. W. Gething, P. M. Atkinson, S. I. Hay, and R.W. Snow. 2006. "Modelling Distances Travelled to Government Health Services in Kenya." Tropical Medicine \& International Health 11(2): 188-196.

29. Quick, J. D., Canavan, C. R., \& Jay, J. (2014). People-centered health systems for UHC. Southern African Journal of Public Health (incorporating Strengthening Health Systems).

30. Regeru, R. N., Chikaphupha, K., Bruce Kumar, M., Otiso, L., \& Taegtmeyer, M. (2020). 'Do you trust those data?' - a mixed-methods study assessing the quality of data reported by community health workers in Kenya and Malawi. Health policy and planning, 35(3), 334-345).

31. Robertson, J., Magrini, N., Barr, R., Forte, G., \& Ondari, C. (2015). Medicines for cancers in children: the WHO model for selection of essential medicines. Pediatric blood \& cancer, 62(10), 16891693.

32. Vitry, A. I., Thai, L., \& Roughead, E. E. (2015). Pharmaceutical pricing policies in Australia. In Pharmaceutical prices in the 21st century (pp. 123). Adis, Cham

33. Wamai, R. (2009). The kenya health system: analysis of the situationandenduringchallenges.JMAJ,52(2),134- 140.

34. WHO (2002). The selection of essential medicine (NO. WHO/2002.2). Geneva: World Health Organization

35. WHO (2010). Monitoring the building blocks of health systems: a handbook of indicator and their measurement strategies. World Health Organization 